\title{
Correction to: Primary Adrenal Gastrointestinal Stromal Tumor (GIST): a Rarest Incidentaloma and Diagnostic Challenge
}

\author{
Akanksha Bhatia $^{1} \cdot$ Arvind Ahuja $^{1} \cdot$ Hemant Goel $^{2} \cdot$ Minakshi Bhardwaj ${ }^{1}$
}

Published online: 26 August 2020

(C) Indian Association of Surgical Oncology 2020

\section{Correction to: Indian Journal of Surgical Oncology} https://doi.org/10.1007/s13193-020-01182-8

There is an error in the page 1, under case report heading line 42 , was to replaced the word "degeneration" with "stroma" but it has been published as "replace degeneration with stroma" in the online version.

The original article has been corrected.

Publisher's Note Springer Nature remains neutral with regard to jurisdictional claims in published maps and institutional affiliations.

The online version of the original article can be found at https://doi.org/ $10.1007 / \mathrm{s} 13193-020-01182-8$

\section{Arvind Ahuja}

drarvindahuja@gmail.com

1 Department of Pathology, Atal Bihari Vajpayee Institute of Medical Sciences, Dr Ram Manohar Lohia Hospital, New Delhi 110001, India

2 Department of Urology Atal Bihari Vajpayee Institute of Medical Sciences, Dr Ram Manohar Lohia Hospital, New Delhi, India 